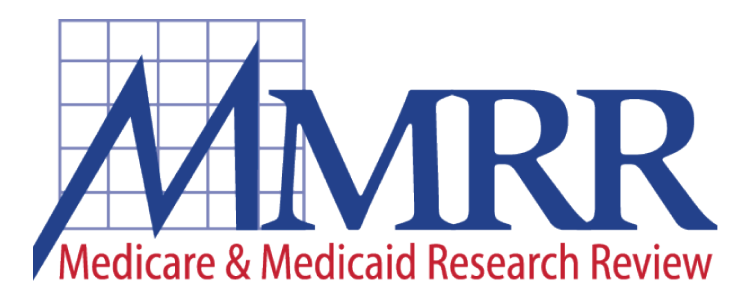

2013: Volume 3, Number 3

A publication of the Centers for Medicare \& Medicaid Services, Office of Information Products \& Data Analytics

\title{
Measuring Prevention More Broadly: An Empirical Assessment of CHIPRA Core Measures
}

\author{
Nir Menachemi, ${ }^{1}$ Justin Blackburn, ${ }^{1}$ David J. Becker, ${ }^{1}$ \\ Michael A. Morrisey, ${ }^{1}$ Bisakha Sen, ${ }^{1}$ Cathy Caldwell ${ }^{2}$ \\ ${ }^{1}$ University of Alabama at Birmingham \\ ${ }^{2}$ Alabama Department of Public Health
}

Objective: To assess limitations of using select Children's Health Insurance Program Reauthorization Act (CHIPRA) core claims-based measures in capturing the preventive services that may occur in the clinical setting.

Methods: We use claims data from ALL Kids, the Alabama Children's Health Insurance Program (CHIP), to calculate each of four quality measures under two alternative definitions: (1) the formal claims-based guidelines outlined in the CMS Technical Specifications, and (2) a broader definition of appropriate claims for identifying preventive service use. Additionally, we examine the extent to which these two claimsbased approaches to measuring quality differ in assessments of disparities in quality of care across subgroups of children.

Results: Statistically significant differences in rates were identified when comparing the two definitions for calculating each quality measure. Measure differences ranged from a 1.9 percentage point change for measure \#13 (receiving preventive dental services) to a 25.5 percentage point change for measure \#12 (adolescent well-care visit). We were able to identify subgroups based upon family income, rural location, and chronic disease status with differences in quality within the core measures. However, some identified disparities were sensitive to the approach used to calculate the quality measure.

Conclusions: Differences in CHIP design and structure, across states and over time, may limit the usefulness of select claims-based core measures for detecting disparities accurately. Additional guidance and research may be necessary before reporting of the measures becomes mandatory.

Keywords: Administrative Data Uses, Children's Health Insurance Program (CHIP, SCHIP), Child and Adolescent Health, Quality of Care / Patient Safety (Measurement)

ISSN: 2159-0354

doi: http://dx.doi.org/10.5600/mmrr.003.03.a04 


\section{Medicare \& Medicaid Research Review} 2013: Volume 3, Number 3

\section{Mission Statement}

Medicare \& Medicaid Research Review is a peerreviewed, online journal reporting data and research that informs current and future directions of the Medicare, Medicaid, and Children's Health Insurance programs. The journal seeks to examine and evaluate health care coverage, quality and access to care for beneficiaries, and payment for health services.

\section{http://www.cms.gov/MMRR/}

\section{U.S. Department of Health \& Human Services Kathleen Sebelius Secretary}

\section{Centers for Medicare \& Medicaid Services Marilyn Tavenner Administrator}

Editor-in-Chief

David M. Bott, Ph.D.

The complete list of Editorial Staff and Editorial Board members may be found on the MMRR Web site (click link): $\underline{\text { MMRR Editorial Staff Page }}$

Contact: $\underline{\text { mmrr-editors@cms.hhs.gov }}$

Published by the Centers for Medicare \& Medicaid Services.

All material in the Medicare \& Medicaid Research

Review is in the public domain and may be duplicated without permission. Citation to source is requested.

\section{Introduction}

As part of the Children's Health Insurance Program Reauthorization Act of 2009 (CHIPRA), the US Department of Health and Human Services identified a set of 24 pediatric health care quality measures. These 24 core measures were carefully selected by a panel of experts after considering the validity, feasibility, and importance of more than 100 candidate measures (deLone \& Hess, 2011; Dougherty, Schiff, \& Mangione-Smith, 2011; Fairbrother \& Simpson, 2011; MangioneSmith, Schiff, \& Dougherty, 2011). The panel's recommendations were also based, in part, on whether Medicaid and CHIP programs generally had readily available data (e.g., administrative billing data, or routinely collected survey data) to ease the calculation of the quality measures. Although reporting remains voluntary, the 24 core measures represent an important opportunity to standardize quality measurement for comparisons across states, over time (deLone \& Hess, 2011; Dougherty et al., 2011; Fairbrother \& Simpson, 2011), and across patient subpopulations (Centers for Medicare \& Medicaid Services, 2011).

Nevertheless, several barriers and challenges are expected before the core quality measures can be used to their full potential. First, the administration and program structure of Medicaid and CHIP differ by state, resulting in different reimbursement models and ultimately differences in how care is delivered. These differences may affect the calculations of each core measure. For example, ALL Kids, the Alabama CHIP, employs a fee-for-service program that utilizes the large Blue Cross Blue Shield of Alabama (BCBSAL) network of providers, and pays provider rates negotiated by BCBSAL. Providers make billing decisions based on the most appropriate billing code that 
reflects the care they rendered, and the billing code that maximizes their reimbursement for a given encounter (VanGeest, Weiner, Johnson, \& Cummins, 2007; Wynia, Cummins, VanGeest, \& Wilson, 2000). The same encounter may be billed differently across programs due to differences in reimbursement rates, limits on preventive services, bundled care, and cost-sharing. The implication is that the billing codes used in quality measure calculations may be a better reflection of what and how something is reimbursable, rather than what exactly happened clinically (Jollis et al., 1993).

In addition to variation in billing practices across states (Bright, Avorn, \& Everitt, 1989; Iezzoni, 1997; Iezzoni et al., 1992), claims data may be suboptimal when capturing quality under the current definitions of CHIPRA core measures. Ideally, CHIPRA quality measures should reflect real-world occurrences rather than simply what is captured in billing claims. While electronic health record (EHR) data might be suitable to this task (Casciato et al., 2012; Gold et al., 2012), not all states or programs may have the resources that this requires. Thus, understanding the limitations of how claims data are used to calculate CHIPRA quality measures is important if the measures are to be used in research and policy decisions.

Given these concerns, ongoing evaluation and assessment of CHIPRA core quality measures is necessary (Mangione-Smith et al., 2011; GreeneMcIntyre \& Caldwell, 2011). In addition, to our knowledge, the measures have not yet been used to examine disparities within programs by race, rural status, socioeconomic status, or other relevant characteristics. Thus, the purpose of this paper is three fold. First, using ALL Kids' structure and reimbursement model as an example, we empirically examined shortcomings of select CHIPRA core quality measures in capturing the preventive services that may occur in the clinical setting. We compared the CMS definition to a broader definition of preventive services delivered clinically for selecting claims to calculate a set of the prevention core measures. Second, we compared performance on this claims-based subset of core measures between various enrollee characteristics including race, age, rural status, and socioeconomic status. Lastly, we combined these two aims and examined the extent to which our two approaches to measuring claims-based quality yielded different conclusions regarding the disparities identified.

\section{Methods}

This study used a retrospective cohort design with administrative claims data of enrollees in Alabama's ALL Kids, a free-standing CHIP. ALL Kids is effectively a fee-for-service plan, and is administered in conjunction with Blue Cross Blue Shield of Alabama (BCBSAL). Claims and enrollment history data obtained from ALL Kids and BCBSAL, from January 2009 through December 2010, were used to calculate the most current quality measures available. Our analysis examined four claims-based quality measures identified from the Initial Core Set of Children's Health Care Quality Measures: Technical Specifications and Resources Manual for Federal Fiscal Year 2011 Reporting (Centers for Medicare \& Medicaid Services, 2011):

- Measure 10: Well-child visits in the first 15 months of life ${ }^{1}$

- Measure 11: Well-child visits in the third, fourth, fifth and sixth years of life

- Measure 12: Adolescent well-care visits

\footnotetext{
${ }^{1}$ Rather than use all 7 rates for Measure 10, children were considered to meet the CMS measure if they received 6 or more well-child visits during the first 15 months of life, as recommended by the American Academy of Pediatrics Guidelines for Health Supervision (http://www.aap.org).
} 
- Measure 13: Percentage of eligible who received preventive dental services

To address the first aim of the study, each included CHIPRA core measure was calculated twice. Once using the claims-based definition from the CMS technical manual-that is, using only the procedure codes that were specified among children meeting eligibility criteria-and a second time using an expanded, more sensitive specification of the claims-based measure that may be more analogous to the CMS hybrid models, but still relies only upon claims. For the second aim, we examined performance on each CHIPRA core measure for various subpopulations as described below. Finally, for the third aim, we examined whether the disparities in performance identified in aim two were sensitive to the alternate definitions of the quality measures.

The definitions expanded beyond the CMS criteria for each CHIPRA core measure used in the current study appear in the appendices. The expanded definitions are designed to include preventive services that are actually received by children, but may not always be captured by the CMS technical manual claims-based definitions due to variations in program and physician billing practices. Briefly, in the case of core measures \#10 through \#12, the expanded definition includes additional procedure and diagnosis codes from the American Academy of Pediatrics (AAP) preventive services guidelines.

One such example is childhood immunizations, which could be administered during office visits that are not billed as a "well-child visit." For example, a child presenting with a cough during a scheduled well-child visit may receive all the appropriate immunizations and screenings of the well visit in addition to an examination for the cough. Under certain reimbursement situations, including limits on the total number of annual well-visits allowable or the potential to get a higher, permissible reimbursement rate, providers may find it beneficial to bill for a sick visit along with an immunization rather than bill for a well-visit. Such a visit would be omitted from the CHIPRA core quality measure count, because the CMS claims-based definition involves computing the frequency of "well-visits" and not necessarily the components of activities and procedures that occur during a well-child visit. In our expanded definitions (analogous to the CMS hybrid definition), we include all visits where children received any of the AAP recommended screenings and/or procedures that are expected as part of well-visits. Furthermore, to account for children who may be behind on immunizations or screenings (e.g., a child who did not receive the $\mathrm{DTaP}$ immunization until age two), our broader definition considered any of the cumulative codes for procedures recommended by the AAP to be received at or below that age.

Similarly, for the preventive dental visits measure (core measure 13, where a CMS hybrid model does not exist), we calculated the use of diagnostic procedures (e.g., routine $\mathrm{x}$-rays) to identify visits by children who may have had some form of preventive dental care that may not have been billed explicitly as a "preventive" visit. By including preventive services not captured by the CMS technical manual definitions, we were able to identify better the "upper bound" of the level of preventive services received by children.

The total number of eligible children (i.e., the denominator) for each quality measure was calculated following the CMS technical manual specifications. For the well-child measures, this required children to have no gap in coverage greater than 45 days during the enrollment period. For the dental measure, gaps of fewer than 90 days were allowable.

Data to identify subpopulations were derived from administrative data maintained by ALL Kids. Age, gender, race, and federal poverty level 
(FPL) were directly available from enrollment data. Race was self-reported during the enrollment application by selecting a categorical value from a single measure. However, ethnicity was not specifically assessed. Due to small sample sizes, racial groups other than Caucasian or African American were combined into a single group. Some ALL Kids enrollees, primarily Native Americans, are exempt from cost-sharing. To identify children in rural areas, we utilized the rural urban commuting area (RUCA) codes based on enrollees' ZIP codes (http://depts.washington.edu/uwruca/). We identified and compared children with a chronic disease to others using a previously identified methodology (Becker et al., 2011). Specifically, we used all available claims data for a given child to identify the presence of a diagnosis code associated with several chronic diseases including HIV, cancer, anemia or coagulation disorders, diabetes, cystic fibrosis, schizophrenic disorders, developmental disorders, infantile cerebral palsy, epilepsy, muscular dystrophy, heart and circulatory diseases or defects, asthma, rheumatoid arthritis, spina bifida, birth trauma, spinal cord injury, and hearing loss.
Statistical analysis comparing the number of enrollees meeting CMS-definition CHIPRA core measures versus the expanded definition of quality measures was performed using McNemar's Test. We used multivariable logistic regressions to identify beneficiary characteristics associated with improved performance on each CHIPRA quality measure. Predicted probabilities of meeting CHIPRA core measures (CMS and expanded definition) were calculated for each covariate at the mean level of all other covariates. Statistically significant differences were determined by calculating marginal effects using the delta method to compare the discrete change from the reference category. Statistical significance was assessed at the $\mathrm{p}<0.05$ level.

\section{Results}

Of the 103,977 children in calendar year 2010 who were enrolled in ALL Kids for at least one month, 89,794 (86\%) met the eligibility criteria for calculation of at least one of the four selected CHIPRA core measures. Descriptive characteristics for these children are shown in Exhibit 1.

Exhibit 1. Description of ALL Kids Enrollees Eligible for at Least One CHIPRA Core Measure Calculation During Calendar Year 2010

Eligible for Calculation

\begin{tabular}{|c|c|c|c|c|c|}
\hline & & & & & Measure 13 \\
\hline & & & & & Percentage \\
\hline & & Well-Child & Well-Child Visits & Measure 12 & of Eligibles \\
\hline & & Visits in & in the $3 \mathrm{rd}, 4 \mathrm{th}$, & Adolescent & That Received \\
\hline & & the First 15 & 5 th, and 6th & Well-Care & Preventive \\
\hline & Total & Months of Life & Years of Life & Visit & Dental Services \\
\hline Variable & $\mathrm{N}=89,794$ & $\mathrm{~N}=427$ & $\mathrm{~N}=7,775$ & $\mathrm{~N}=24,333$ & $\mathrm{~N}=89,649$ \\
\hline Age at first observation, & - & - & - & - & 11.3 \\
\hline mean $(\mathrm{SD})$ & & & & & $(4.78)$ \\
\hline Male, n (\%) & 45,158 & 222 & 3,968 & 12,307 & 45,116 \\
\hline & $(50.3)$ & $(52.0)$ & $(51.0)$ & $(50.6)$ & $(50.3)$ \\
\hline Federal Poverty Level, n & & & & & \\
\hline $101-150 \%$ & 53,236 & 127 & 2,530 & 14,640 & 50,963 \\
\hline & $(59.3)$ & $(29.7)$ & $(32.5)$ & $(60.2)$ & $(56.9)$ \\
\hline
\end{tabular}

(Continued) 
Exhibit 1 Continued. Description of ALL Kids Enrollees Eligible for at Least One CHIPRA Core Measure Calculation During Calendar Year 2010

Eligible for Calculation

\begin{tabular}{|c|c|c|c|c|c|}
\hline & & & & & Measure 13 \\
\hline & & Measure 10 & Measure 11 & & Percentage \\
\hline & & Well-Child & Well-Child Visits & Measure 12 & of Eligibles \\
\hline & & Visits in & in the $3 \mathrm{rd}, 4 \mathrm{th}$, & Adolescent & That Received \\
\hline & & the First 15 & 5th, and 6th & Well-Care & Preventive \\
\hline & Total & Months of Life & Years of Life & Visit & Dental Services \\
\hline Variable & $\mathrm{N}=89,794$ & $\mathrm{~N}=427$ & $\mathrm{~N}=7,775$ & $\mathrm{~N}=24,333$ & $\mathrm{~N}=89,649$ \\
\hline $151-200 \%$ & 29,944 & 220 & 3,898 & 7,261 & 29,045 \\
\hline & $(33.4)$ & $(51.5)$ & $(50.1)$ & $(29.8)$ & $(32.4)$ \\
\hline $201-300 \%$ & 5,891 & 80 & 1,299 & 2,215 & 729 \\
\hline & $(6.6)$ & $(18.7)$ & $(16.7)$ & $(9.1)$ & $(0.8)$ \\
\hline Exempt & 723 & 0 & 48 & 217 & 8,912 \\
\hline & $(0.8)$ & $(0.0)$ & $(0.6)$ & $(0.9)$ & $(9.9)$ \\
\hline Rural/Urban Code, n (\%) & & & & & \\
\hline Urban & 59,357 & 327 & 5,431 & 15,728 & 59,222 \\
\hline & $(66.1)$ & $(76.6)$ & $(68.9)$ & $(64.6)$ & $(66.1)$ \\
\hline Large rural city/town & 11,026 & 43 & 849 & 3,123 & 10,989 \\
\hline & $(12.3)$ & $(10.1)$ & $(10.9)$ & $(12.8)$ & $(12.3)$ \\
\hline Small rural town & 11,158 & 34 & 892 & 3,044 & 11,114 \\
\hline & $(12.4)$ & $(8.0)$ & $(11.5)$ & $(12.5)$ & $(12.4)$ \\
\hline Isolated small rural town & 7,817 & 23 & 568 & 2,357 & 7,805 \\
\hline & $(8.7)$ & $(5.4)$ & $(7.3)$ & $(9.7)$ & $(8.7)$ \\
\hline Unknown & 436 & 0 & 35 & 81 & 519 \\
\hline & $(0.5)$ & $(0.0)$ & $(0.5)$ & $(0.3)$ & $(0.6)$ \\
\hline Race, $\mathrm{n}(\%)$ & & & & & \\
\hline Caucasian & 51,897 & 247 & 4,880 & 13,839 & 45,027 \\
\hline & $(57.8)$ & $(57.9)$ & $(62.8)$ & $(56.9)$ & $(50.2)$ \\
\hline African American & 30,522 & 119 & 2,063 & 8,920 & 26,737 \\
\hline & $(34.0)$ & $(27.9)$ & $(25.5)$ & $(36.7)$ & $(29.8)$ \\
\hline Other & 7,305 & 61 & 832 & 1,574 & 17,885 \\
\hline & $(8.1)$ & $(14.3)$ & $(10.7)$ & $(6.5)$ & $(20.0)$ \\
\hline Chronic disease, n (\%) & 14,214 & 69 & 996 & 4,195 & 14,189 \\
\hline & $(15.8)$ & $(16.2)$ & $(12.8)$ & $(17.2)$ & $(15.8)$ \\
\hline
\end{tabular}

NOTE: The Federal Poverty Level (FPL) was $\$ 22,050$ for a family of 4 in 2010. Some ALL Kids enrollees, primarily Native Americans, are exempt from cost-sharing and thus do not report FPL data.

SOURCE: Author's analysis.

For each of the selected quality measures, the expanded definition yielded a statistically significant increase in the proportion of enrollees meeting that measure, relative to the CMS definition (see Exhibit 2). A 25.5 percentage point increase $(36.4 \%$ vs. $61.9 \%$; $\mathrm{p}<0.001)$ was observed between the CMS definition and expanded rate for adolescent well-care visits (measure 13), the largest difference of all comparisons. Sizable differences were also observed for well-child visits 
Exhibit 2. ALL Kids Enrollees Meeting Selected CHIPRA Core Measures as Compared to Those Meeting the Expanded Measure Definition.

\begin{tabular}{|c|c|c|c|}
\hline & \multicolumn{2}{|c|}{ Number of Individuals that: } & \multirow[b]{3}{*}{$p$} \\
\hline & & Meet Expanded & \\
\hline & $\begin{array}{l}\text { Meet Measure } \\
\qquad \mathrm{N}(\%)\end{array}$ & $\begin{array}{l}\text { Measure } \\
\mathrm{N}(\%)\end{array}$ & \\
\hline $\begin{array}{l}\text { Measure 10: Well-Child Visits in the First } 15 \text { Months of Life } \\
(\mathrm{N}=431)\end{array}$ & $201(46.6)$ & $256(59.4)$ & $<.0001$ \\
\hline $\begin{array}{l}\text { Measure 11: Well-Child Visits in the Third, Fourth, Fifth } \\
\text { and Sixth Years of Life }(\mathrm{N}=7,775)\end{array}$ & $5,343(68.7)$ & $6,314(81.2)$ & $<.0001$ \\
\hline Measure 12: Adolescent Well-Care Visits $(\mathrm{N}=24,333)$ & $8,865(36.4)$ & $15,073(61.9)$ & $<.0001$ \\
\hline Measure 13: Percentage of Eligibles That Received & $52,433(58.5)$ & $54,188(60.4)$ & $<.0001$ \\
\hline Preventive Dental Services $(\mathrm{N}=89,649)$ & & & \\
\hline
\end{tabular}

SOURCE: Author's analysis.

during the first 15 months of life (measure 10; $46.6 \%$ vs. $59.4 \%$; $\mathrm{p}<0.001)$ and well-child visits in the 3rd to 6th years of life (measure $11 ; 68.7 \%$ vs. $81.2 \% ; \mathrm{p}<0.001)$. The expanded definition of measure 12 for preventive dental services yielded a rate that was 1.9 percentage points greater than the rate calculated with the CMS definition (58.5\% vs. 60.4\%; $\mathrm{p}<0.001)$.

Exhibit 3 presents the predicted probabilities of a series of regression analyses that examine the relationship between enrollee characteristics and performance on each of the selected CHIPRA core measures. We observed a strong positive relationship between family income and all four quality measures based on the CMS definitions. The largest effect was observed among measure 10 (well-child visits in the first 15 months of life) between enrollees at 101-150\% FPL compared to $201-300 \%$ (predicted probability $38.5 \%$ vs. $62.1 \%$, $\mathrm{p}<0.001)$. Rural children fared worse on all of the quality measures with the exception of measure 10 (well-child visits in the first 15 months of life). This was particularly evident among adolescent children in isolated small rural towns, who were 17.4 percentage points less likely to meet measure
12 (adolescent well-care visit) compared to urban children $(22.7 \%$ vs. $40.2 \%, \mathrm{p}<0.001)$. Children with chronic diseases were found to have an overall greater likelihood of meeting measure 11 (well-child visits in the 3rd-6th years of life), measure 12 (adolescent well-care visit), and measure 13 (received preventive dental services). This effect had the greatest magnitude for measure 11 (well-child visits in the 3rd-6th years of life), where children with a chronic disease had a 10.2 percentage point greater likelihood of compliance than other children $(77.9 \%$ vs. $67.7 \%, \mathrm{p}<0.001)$.

Age was only evaluated for measure 13 (preventive dental services), since other measures had inherently restricted age groups. We observe a positive monotonic relationship between age and the receipt of recommended preventive dental services. Compared to children aged 1 to 2 years, which is the minimum age for calculating the measure, children aged 3 to 6 years were 45.9 percentage points more likely to have met the measure $(57.4 \%$ vs. $16.9 \%, \mathrm{p}<0.001)$; children aged 7 to 11 years were 56.6 percentage points more likely $(67.7 \%$ vs. $16.9 \%, \mathrm{p}<0.001)$; and children aged 12 to 19 years were 43.6 percentage 
Exhibit 3. Comparing the Performance of Subgroups on Select CHIPRA Core Measures Using CMS and Expanded Definitions (numbers displayed are predicted probabilities of meeting the measure, converted to percent)

\begin{tabular}{|c|c|c|c|c|c|c|c|c|}
\hline \multirow[b]{3}{*}{ Variable } & \multicolumn{6}{|c|}{ Measure 11} & \multirow{2}{*}{\multicolumn{2}{|c|}{$\begin{array}{c}\text { Measure } 13 \\
\text { Percentage of } \\
\text { Eligibles That } \\
\text { Received Preventive } \\
\text { Dental Services }\end{array}$}} \\
\hline & \multicolumn{2}{|c|}{$\begin{array}{c}\text { Measure } 10 \\
\text { Well-Child Visits } \\
\text { in the First } 15 \\
\text { Months of Life }\end{array}$} & \multicolumn{2}{|c|}{$\begin{array}{l}\text { Well-Child Visits in } \\
\text { the 3rd, } 4 \text { th, } \\
5 \text { th, and 6th Years } \\
\text { of Life }\end{array}$} & \multicolumn{2}{|c|}{$\begin{array}{c}\text { Measure } 12 \\
\text { Adolescent Well- } \\
\text { Care Visit }\end{array}$} & & \\
\hline & CMS & Expanded & CMS & Expanded & CMS & Expanded & CMS & Expanded \\
\hline \multicolumn{9}{|l|}{ Age } \\
\hline 1 to 2 years (reference) & - & - & - & - & - & - & 16.9 & 22.3 \\
\hline 3 to 6 years & - & - & - & - & - & - & $57.4^{* * *}$ & $59.6^{* * *}$ \\
\hline 7 to 11 years & - & - & - & - & - & - & $67.7^{\star * *}$ & $68.9^{* * *}$ \\
\hline 12 to 19 years & - & - & - & - & - & - & $55.1^{\star \star \star}$ & $57.4^{\star \star \star}$ \\
\hline \multicolumn{9}{|l|}{ Gender } \\
\hline Male (reference) & 44.2 & 56.1 & 69.2 & 81.5 & 34.1 & 55.3 & 56.8 & 58.7 \\
\hline Female & 48.8 & 62.9 & 69.0 & 82.7 & $37.8^{* * *}$ & $69.4^{\star \star \star}$ & $60.3^{\star * *}$ & $62.6^{\star * *}$ \\
\hline \multicolumn{9}{|l|}{ Federal Poverty Level } \\
\hline $101-150 \%$ (reference) & 38.5 & 55.2 & 66.8 & 79.9 & 34.1 & 60.8 & 56.9 & 59.1 \\
\hline $151-200 \%$ & 45.3 & 57.5 & $69.3^{* *}$ & $82.5^{\star *}$ & $38.3^{* * *}$ & $64.8^{\star * *}$ & 59.4 & $61.4^{\star * \star}$ \\
\hline $201-300 \%$ & $62.1^{\star * *}$ & $70.2^{\star *}$ & $72.6^{* * *}$ & $84.2^{* * *}$ & $41.6^{* * *}$ & $66.2^{\star * *}$ & $61.5^{\star * *}$ & $66.4^{* * *}$ \\
\hline Exempt & - & - & 76.3 & $94.2^{\star *}$ & 28.5 & $68.3^{\star *}$ & $64.5^{\star \star}$ & $64.4^{\star *}$ \\
\hline \multicolumn{9}{|l|}{ RUCA } \\
\hline Urban (reference) & 47.3 & 60.7 & 72.4 & 83.6 & 40.2 & 64.9 & 59.0 & 61.1 \\
\hline Large rural city/town & 46.4 & 59.0 & $64.7^{\star \star \star}$ & $82.0^{\star * *}$ & $34.7^{\star * *}$ & $62.4^{\star \star}$ & 59.2 & 61.4 \\
\hline Small rural town & 39.5 & 57.8 & $58.5^{\star * *}$ & $74.8^{\star * *}$ & $28.2^{* * *}$ & $58.7^{\star * *}$ & $56.3^{\star * *}$ & $58.6^{\star * *}$ \\
\hline Isolated rural town & 43.4 & 42.6 & $58.8^{\star * *}$ & $77.1^{\star * *}$ & $22.7^{\star * *}$ & $51.8^{\star * *}$ & $57.5^{\star \star}$ & $59.6^{* *}$ \\
\hline Unknown & - & - & 57.2 & 77.4 & $23.2^{\star * *}$ & 56.5 & $46.9^{\star * *}$ & $49.4^{\star * *}$ \\
\hline \multicolumn{9}{|l|}{ Race } \\
\hline Caucasian (reference) & 48.3 & 62.4 & 68.9 & 82.3 & 32.2 & 62.1 & 61.3 & 63.6 \\
\hline African American & 55.2 & 67.4 & 69.8 & 81.5 & $41.6^{* * *}$ & 63.1 & $59.0^{* * *}$ & $60.9^{* * *}$ \\
\hline Other / Unknown & $24.2^{\star * *}$ & $30.8^{\star * *}$ & 68.7 & 82.0 & $38.5^{* * *}$ & 63.2 & $50.3^{\star * *}$ & $52.3^{\star * *}$ \\
\hline \multicolumn{9}{|l|}{ Chronic Disease } \\
\hline Absent (reference) & 46.9 & 58.4 & 67.7 & 79.8 & 34.8 & 59.4 & 57.5 & 59.6 \\
\hline Present & 43.8 & 64.3 & $77.9^{\star \star \star}$ & $92.7^{\star \star \star}$ & $41.4^{* * *}$ & $76.2^{\star \star *}$ & $63.4^{\star \star \star}$ & $65.7^{\star \star \star}$ \\
\hline
\end{tabular}

points more likely $(55.1 \%$ vs. $16.9 \%, \mathrm{p}<0.001)$. Race had an inconsistent relationship across the examined CHIPRA core measures. Whereas, on measure 12 (adolescent well-care visits),
African Americans and "other" races were more likely than Caucasians to be in compliance with the measure by 9.5 and 6.4 percentage points, respectively ( $41.6 \%$ vs. $32.2 \%$, p $<0.001 ; 38.5 \%$ vs. 
$32.2 \%, \mathrm{p}<0.001$ ); Caucasian children were more likely to meet measures 10 (well child visits in the first 15 months of life) and 13 (received preventive dental services). Female gender was associated with a greater likelihood of meeting measure 12 (adolescent well-care visits) and measure 13 (received preventive dental services).

These observed differences across subpopulations were sensitive to the use of our expanded definition of the claims-based quality measures. For the calculation of measure 12 (adolescent well child visits) using the CMS definition, the exempt FPL group (composed mostly of Native Americans) did not differ from those at the lowest FPL (28.5\% vs. $34.1 \%, \mathrm{p}=0.085$ ). However, using the expanded definition, we observed that enrollees in the exempt FPL group were more likely to be in compliance with this measure $(68.3 \%$ vs. $60.8 \%, \mathrm{p}=0.029)$. Similarly, whereas African Americans and those of "other" races were more likely than Caucasians to be in compliance with measure 12 (adolescent well-care visits) using the CMS definition, the differences were not detected in the model that utilized the expanded definition for this measure.

\section{Discussion}

Our study, which focused on select CHIPRA core measures, suggests that performance rates identified using CMS claims-based definitions may not fully capture the preventive care services received by ALL Kids enrollees. Furthermore, we identified situations where disparities on certain quality measures were sensitive to how the measures were calculated. One of the key benefits of developing the set of measures as stated by CMS is that the measures will "standardize reporting and make access to quality data more available to States for comparison purposes" (Centers for Medicare \& Medicaid Services, 2011). However, our results raise questions about whether different policy or structures of states' CHIP and Medicaid programs could result in differences in delivery of care and/or billing practices, which in turn could affect the usefulness of these quality measures in comparing states to each other or across time. For example, to assure reimbursement in programs where children have a limited number of reimbursable well-child visits, providers may deliver preventive care components during office visits other than well-visits. Physician reimbursement has previously been linked to preventive care, specifically well-visits, immunizations, and preventive dental in both commercial and public health insurance (Hickson, Altemeier, \& Perrin, 1987; Kenney, Marton, Klein, Pelletier, \& Talbert, 2011; McInerny, Cull, \& Yudkowsky, 2005). Thus, it is difficult to discern whether the claims-based CHIPRA core quality measures as defined are the best measure of quality possible, or subject to variation introduced as a byproduct of programmatic policies.

Although additional refinement may be necessary, CHIPRA core quality measures appear to be useful for identifying health care quality differences among subpopulations. We found that several subgroups associated with limited access and/or resources (e.g., lowest income group, most rural group) experience poorer performance on select measures. This information can be particularly useful to guide program policy and the allocation of resources to better serve certain enrollees. However, some of the differences among subgroups we found were sensitive to the definition of the measure used (i.e., CMS or expanded). This is consistent with the finding by Casciato et al. (2012) who examined adjustments to parameters in the calculation of CHIPRA core measures using EHRs. Taken together, this suggests certain subpopulations may be more likely to receive elements of preventive care (e.g., immunizations) during visits not coded on claims records as well-child care. Thus, more research on how the measures can best be used for identifying differences among subgroups of enrollees is warranted.

Our analysis should be interpreted in light of some limitations. Our analysis is of a single CHIP in a single state, and the results may not apply generally to other programs or states. In addition, our analysis only focused on a handful of CHIPRA core measures-all of which use claims data only and focus on prevention. Future studies should examine the opportunities for the improvement of other quality measures as well. Moreover, our study 
was cross-sectional in nature. Thus, we are unable to comment with certainty on the effectiveness of a given measure (however standardized) when used to examine trends over time. Future research will need to examine the internal consistency (e.g., reliability) of each CHIPRA core measure. Lastly, it is important to note that our analysis was not designed to detect the empirical validity of any of the measures. Despite the face-validity and expert consensus supporting many of the measures, more research will be needed to directly link desirable performance to actual clinical and/or cost outcomes.

Overall, we believe that the initial CHIPRA core measures can be useful in our nation's effort to improve the quality of pediatric care and to reduce disparities among subgroups of children. However, our analysis identified several areas of concern that should be addressed with more research or guidance before the measures can live up to their fullest expectations. Specifically, certain attributes of individual CHIP or Medicaid programs (e.g., programmatic policies governing well-visits) may make it difficult to get accurate information about the quality that occurs in the clinical setting. Furthermore, based upon our findings, calculating the core measures under the current CMS claims-based definitions may result in reduced or overlooked disparities in care quality. Future research should expand beyond a single program to determine how alternative program structures and policies impact the calculation of CHIPRA core measures and whether or not our findings about disparities may be applied generally.

\section{Correspondence}

Nir Menachemi, Ph.D., M.P.H., University of Alabama at Birmingham-Health Care Organization \& Policy, 1720 2nd Ave.S., Birmingham, AL 35294-0022,nmenachemi@ uab.edu, Tel. 205-974-7192, Fax. 205-934-3347

\section{References}

Becker, D. J., Blackburn, J. L., Kilgore, M. L., Morrisey, M. A., Sen, B., Caldwell, C., \& Menachemi, N. (2011, October). Continuity of insurance coverage and ambulatory caresensitive hospitalizations/ED visits: evidence from the children's health insurance program. Clinical Pediatrics, 50, 963-973. PubMed http:// dx.doi.org/10.1177/0009922811410229

Bright, R. A., Avorn, J., \& Everitt, D. E. (1989). Medicaid data as a resource for epidemiologic studies: strengths and limitations. Journal of Clinical Epidemiology, 42, 937-945. PubMed http://dx.doi.org/10.1016/0895-4356(89)90158-3

Casciato, A., Angier, H., Milano, C., Gideonse, N., Gold, R., \& DeVoe, J. (2012, SeptemberOctober). Are pediatric quality care measures too stringent? Journal of the American Board of Family Medicine, 25, 686-693. PubMed http:// dx.doi.org/10.3122/jabfm.2012.05.120041

Centers for Medicare \& Medicaid Services. (2011, December). Initial Core Set of Children's Health Care Quality Measures: Technical Specifications and Resource Manual for Federal Fiscal Year 2011 Reporting. Retrieved from http://64.64.16.103/wp-content/uploads/2013/01/ initialcoresetresoucemanual.pdf

deLone, S. E. \& Hess, C. A. (2011, May-June). Medicaid and CHIP Children's healthcare quality measures: What states use and what they want. Academic Pediatrics, 11(3, Suppl), S68-S76. PubMed http://dx.doi.org/10.1016/j. acap.2010.12.003

Dougherty, D., Schiff, J., \& Mangione-Smith, R. (2011, May-June). The Children's Health Insurance Program Reauthorization Act Quality Measures Initiatives: Moving forward to improve measurement, care, and child and adolescent outcomes. Academic Pediatrics, 11(3, Suppl), S1-S10. PubMed http://dx.doi.org/10.1016/j. acap.2011.02.009

Fairbrother, G. \& Simpson, L. A. (2011, May-June). Measuring and reporting quality of health care 
for children: CHIPRA and beyond. Academic Pediatrics, 11(3, Suppl), S77-S84. PubMed http://dx.doi.org/10.1016/j.acap.2010.10.003

Gold, R., Angier, H., Mangione-Smith, R., Gallia, C., McIntire, P. J., Cowburn, S., ... DeVoe, J. E. (2012, July). Feasibility of evaluating the CHIPRA care quality measures in electronic health record data. Pediatrics, 130, 139-149. PubMed http://dx.doi. org/10.1542/peds.2011-3705

Greene-McIntyre, M. \& Caldwell, C. (2011, May-June). State Medicaid and Children's Health Insurance Program's perspective on CHIPRA Core Measures. Academic Pediatrics, 11(3, Suppl), S89-S90. PubMed http://dx.doi. org/10.1016/j.acap.2010.07.007

Hickson, G. B., Altemeier, W. A., \& Perrin, J. M. (1987, September). Physician reimbursement by salary or fee-for service: effect on physician practice behavior in a randomized prospective study. Pediatrics, 80, 344-350. PubMed

Iezzoni, L. I. (1997, October). Assessing quality using administrative data. Annals of Internal Medicine, 127, 666-674. PubMed http:// dx.doi.org/10.7326/0003-4819-127-8_Part_2199710151-00048

Iezzoni, L. I., Foley, S. M., Daley, J., Hughes, J., Fisher, E. S., \& Heeren, T. (1992, April). Comorbidities, complications, and coding bias: Does the number of diagnosis codes matter in predicting in-hospital mortality? Journal of the American Medical Association, 267, 2197-2203. PubMed http://dx.doi.org/10.1001/ jama.267.16.2197

Jollis, J. G., Ancukieewicz, M., DeLong, E. R., Pryor, D. B., Muhlbaier, L. H., \& Mark, D. B. (1993, October). Discordance of databases designed for claims payment versus clinical information systems. Implications for outcomes research. Annals of Internal Medicine, 119, 844850. PubMed http://dx.doi.org/10.7326/00034819-119-8-199310150-00011

Kenney, G. M., Marton, J., Klein, A. E., Pelletier, J. E., \& Talbert, J. (2011, February). The effects of Medicaid and CHIP policy changes on receipt of preventive care among children. Health Services Research, 46(1, Pt. 2), 298-318. doi: http://dx.doi.org/10.1111/j.14756773.2010.01199.x PubMed

Mangione-Smith, R., Schiff, J., \& Dougherty, D. (2011, May-June). Identifying children's health care quality measures for Medicaid and CHIP: An evidence-informed, publicly transparent expert process. Academic Pediatrics, 11(3, Suppl), S11-S21. PubMed http://dx.doi.org/10.1016/j. acap.2010.11.003

McInerny, T. K., Cull, W. L., \& Yudkowsky, B. K. (2005, April). Physician reimbursementlevels and adherence to American Academy of Pediatrics well-visit and immunization recommendations. Pediatrics, 115, 833-838. PubMed http://dx.doi. org/10.1542/peds.2004-1510

VanGeest, J., Weiner, S., Johnson, T., \& Cummins, D. (2007, July).Impactofmanaged careonphysicians' decisions to manipulate reimbursement rules: an explanatory model. Journal of Health Services Research \& Policy, 12, 147-152. PubMed http:// dx.doi.org/10.1258/135581907781543102

Wynia, M. K., Cummins, D. S., VanGeest, J. B., \& Wilson, I. B. (2000, April). Physician manipulation of reimbursement rules for patients: between a rock and a hard place. Journal of the American Medical Association, 283, 1858-1865. PubMed http://dx.doi.org/10.1001/ jama.283.14.1858 


\section{Appendix A}

Exhibit A1. Additional Preventative Service Billing Codes used for Constructing the Expanded Definitions of select CHIPRA Core Measures.

\begin{tabular}{ll}
\hline Description $^{1}$ & \multicolumn{2}{c}{ ICD9/CPT4 Codes } \\
\hline & \multicolumn{2}{c}{ Measure \#10 } \\
$\begin{array}{l}\text { Hereditary/metabolic screening: Includes newborn } \\
\text { metabolic screening panel (thyroid, phenylketonuria, }\end{array}$ & V72.6, V77.0, V77.3, V77.4, V77.7, V77.99, V78.0, \\
$\begin{array}{l}\text { galactosemia, inborn errors, unspecified iron deficiency } \\
\text { anemia, unspecified anemia, sickle cell disease, }\end{array}$ & \\
$\begin{array}{l}\text { hemoglobinopathies, blood disorders) and laboratory exam } \\
\text { Hematocrit or hemoglobin: Includes blood count }\end{array}$ & 85014,85018 \\
$\begin{array}{l}\text { hematocrit, blood count hemoglobin } \\
\text { Urinalysis: Includes nonautomated with microscopy, }\end{array}$ & V72.6, V77.1, V77.99, 81000, 81001, 81002, 81003
\end{tabular}
automated with microscopy, nonautomated without microscopy, automated without microscopy, diabetes, unspecified, lab exam

Immunizations: Includes general immunization

V03.81, V03.82, V04.0, V04.81, V04.89, V05.3, administration, Hep B, rotavirus, DTaP, $\mathrm{HiB}$, pneumococcal, Poliovirus, influenza, MMR, varicella, Hep A V05.4, V05.9, V06.1, V06.3, V06.4, V06.5, V06.8, V06.9, C9105, G0008, G0009, G0010, 90460 90461, 90471, 90472, 90473, 90474, 90633, 90634, 90644, 90645, 90646, 90647, 90648, 90655, 90657, 90660, 90661, 90669, 90670, 90680, 90681, 90698, 90700, 90701, 90702, 90707, 90710, 90712, 90713, 90716, 90721, 90723, 90740, 90743, 90744, 90746, 90747, 90748

Measure \#11

Immunizations: Includes DTaP, influenza, pneumococcal V V03.82, V03.89, V04.81, V06.3, 90655, 90656, (PPSV), meningococcal $90658,90696,90723,90733,90734$

Measure \#12

Immunizations: Includes Td, HPV

V04.8, V06.1, V06.5, 90649, 90650, 990714, 90715, 90718 ,

NOTE: ${ }^{1}$ Descriptions here are those of the author and do not include the official CPT descriptions maintained by the American Medical Association.

SOURCE: Adapted from American Association of Pediatrics guidelines (http://www.aap.org).

CPT only copyright 2012 American Medical Association and is a registered trademark. All rights reserved. 


\section{Appendix B}

Exhibit B1. Additional Billing Codes used When Constructing the Expanded Definition of CHIPRA Core Measure \#13. All of these Codes are Considered 'Preventive' in the all Kids Program and are not Subject to Copayment.

\begin{tabular}{|c|c|c|c|}
\hline \multirow{2}{*}{$\begin{array}{l}\text { CPT4 } \\
\text { Code }\end{array}$} & \multirow[b]{2}{*}{ Description $^{1}$} & \multicolumn{2}{|l|}{ CPT4 } \\
\hline & & Code & Description $^{1}$ \\
\hline D0120 & PERIODIC ORAL EVAL & D0460 & PULP VITALITY TEST \\
\hline D0140 & LIMT ORAL EVAL PRBLM FOC & D0470 & DIAGNOSTIC CASTS \\
\hline D0145 & ORAL EVALUATION, $\mathrm{PT}<3 \mathrm{Y}$ & D0472 & ACCESS TISSUE \\
\hline D0150 & COMPREHENSIVE ORAL EVAL & D0473 & ACCESS TISSUE W MICRO EX \\
\hline D0160 & EXTEN ORAL EVAL PROB FOC & D0474 & ACCESS TISSUE, SURG MARG \\
\hline D0170 & RE-EVAL LIMIT PF EST PT & D0475 & DECALCIFICATION PROCEDUR \\
\hline D0180 & COMP PERIODONTAL EVAL & D0476 & SPEC STAINS FOR MICROORG \\
\hline D0210 & INTRAOR COMPL FILM SERI & D0477 & SPEC STAINS NOT FOR MICR \\
\hline D0220 & INTRAOR PERIAPICL 1stFL & D0478 & IMMUNOHISTOCHEMICAL STAI \\
\hline D0230 & INTRAOR PERIAPICL EA AD & D0479 & TISSUE IN-SITU HYBRIDIZA \\
\hline D0240 & INTRAORAL OCCLUSAL FILM & D0480 & PROC\&INTERP CYTOL SMEAR \\
\hline D0250 & EXTRAORAL FIRST FILM & D0481 & ELECTRON MICROSCOPY DIAG \\
\hline D0260 & EXTRAORAL EA ADD FILM & D0482 & DIRECT IMMUNOFLUORESCENC \\
\hline D0270 & DENT BITEWING SNG FLIM & D0483 & INDIRECT IMMUNOFLUORESCE \\
\hline D0272 & DENT BITEWINGS TWO FILM & D0484 & CONSULT SLIDES PREP ELSE \\
\hline D0273 & BITEWINGS - THREE FILMS & D0485 & CONSULT INC PREP OF SLID \\
\hline D0274 & DENT BITEWING FOUR FILM & D0486 & ACCESSION OF BRUSH BIOPS \\
\hline D0277 & VERT BITEWINGS 7-8 FILMS & D0502 & OTHER ORAL PATH PROC \\
\hline D0290 & DENT FLM SKULL/FACE BON & D0999 & UNSPECIFIED DIAG PROC \\
\hline D0310 & DENTAL SALIOGRAPHY & D1110 & DENT PROPHYLAXIS ADULT \\
\hline D0320 & DENT TMJ ARTHROGRM INCL & D1120 & DENT PROPHYLAXIS CHILD \\
\hline D0321 & DENTAL OTHER TMJ FILMS & D1203 & TOPI FLUOR NO PROPH CHI \\
\hline D0322 & DENT TOMOGRAPHIC SURVEY & D1204 & TOPI FLUOR NO PROPH ADU \\
\hline D0330 & DENTAL PANORAMIC FILM & D1206 & TOPICAL FLUORIDE VARNISH \\
\hline D0340 & DENT CEPHALOMETRIC FILM & D1310 & NUTR COUNSL-CONTRL CARI \\
\hline D0350 & ORAL/FACIAL IMAGES & D1320 & TOBACCO COUNSELING \\
\hline D0360 & CONE BEAM CT & D1330 & ORAL HYGIENE INSTRUCT \\
\hline D0362 & CONE BEAM, TWO DIMENSION & D1351 & DENTAL SEALANT/TOOTH \\
\hline D0363 & CONE BEAM, THREE DIMENSI & D1510 & SPACE MAINT FXD UNILAT \\
\hline D0415 & BACTERIOLOGIC STUDY & D1515 & FIXED BILAT SPACE MAINT \\
\hline D0416 & VIRAL CULTURE & D1520 & REMV UNILAT SPACE MAINT \\
\hline D0421 & GEN TST SUSCEPT ORAL DIS & D1525 & REMV BILAT SPACE MAINT \\
\hline D0425 & CARIES SUSCEPTIBIL TEST & D1550 & RECEMENT SPACE MAINTAIN \\
\hline D0431 & DIAG TST DETECT MUCOS AB & D1555 & REMOVE FIX SPACE MAINTAI \\
\hline
\end{tabular}

NOTE: ${ }^{1}$ Descriptions here are those of the author and do not include the official CPT descriptions maintained by the American Medical Association. SOURCE: ALL Kids benefit information (http://www.adph.org/allkids/assets/spd.pdf), CPT4 codes provided by ALL Kids administration. CPT only copyright 2012 American Medical Association and is a registered trademark. All rights reserved. 